\title{
DEVELOPMENT OF A SMA-BASED, SLAT-COVE FILLER FOR REDUCTION OF AEROACOUSTIC NOISE ASSOCIATED WITH TRANSPORT-CLASS AIRCRAFT WINGS
}

\author{
Travis L. Turner \\ Structural Acoustics Branch \\ NASA Langley Research Center \\ Hampton, VA 23681-2199
}

\author{
Reggie T. Kidd \\ Aeronautical Systems Engineering Branch \\ Analytical Mechanics Associates \\ Hampton, VA 23681-2199
}

\author{
Darren J. Hartl and William D. Scholten \\ Department of Aerospace Engineering \\ Texas A\&M University \\ College Station, TX 77843-3141
}

\begin{abstract}
Airframe noise is a significant part of the overall noise produced by typical, transport-class aircraft during the approach and landing phases of flight. Leading-edge slat noise is a prominent source of airframe noise. The concept of a slat-cove filler was proposed in previous work as an effective means of mitigating slat noise.

Bench-top models were developed at $75 \%$ scale to study the feasibility of producing a functioning slat-cove filler. Initial results from several concepts led to a more-focused effort investigating a deformable structure based upon pseudoelastic SMA materials. The structure stows in the cavity between the slat and main wing during cruise and deploys simultaneously with the slat to guide the aerodynamic flow suitably for low noise.

A qualitative parametric study of SMA-enabled, slat-cove filler designs was performed on the bench-top. Computational models were developed and analyses were performed to assess the displacement response under representative aerodynamic load. The bench-top and computational results provide significant insight into design trades and an optimal design.
\end{abstract}

\section{INTRODUCTION}

Conventional transport aircraft wing design is driven mainly by cruise efficiency, i.e., adequate lift is generated at high speed for level flight with minimal drag. Conventional high-lift systems, e.g., leading-edge slats and trailing-edge flaps, were designed to augment lift and stall characteristics at the low speeds required for landing. In current practice, these multi-element airfoil systems are deployed only when in the high-lift configuration during low-speed flight and, thereby, generate greater lift than would be possible with a single airfoil element. The airfoil elements nest together tightly in the cruise configuration to minimize drag, with the leading edge of each element, after the foremost, fitting into a cove in the aft, lower surface of the preceding element. Multi-element airfoil systems also present many geometric discontinuities, e.g., cavities, gaps and edges, to the flow when in the deployed, high-lift configuration. The unsteady aerodynamics caused by these discontinuities is a source for significant aeroacoustic noise, termed airframe noise.

The flow characteristics, noise production mechanisms and notional concepts for slat noise mitigation have been studied extensively. Concepts proposed for reduction of leading-edgeslat noise include brushes [1], extended blade seals [2] and slatcove fillers [3]. The slat-cove filler (SCF) concept was introduced approximately ten years ago as a potential way to fill the cavity behind the deployed slat and guide the flow along a desirable path in order to reduce the unsteadiness and, thereby, reduce the radiated acoustic noise. Progress in this area has been stymied by the difficulty in producing a functioning SCF that can achieve the highly-disparate shapes that are required for the clean, retracted, cruise configuration and the separated, deployed, high-lift configuration.

The objectives of this work were to develop a structural concept to meet the application requirements, including achievement of the disparate configurations and sustainment of the aerodynamic load, and to demonstrate the feasibility and 
practical functionality of the concept. The challenging requirements of the application necessitated unconventional materials and atypical structural approaches. Physical and computational modeling efforts were conducted in parallel because of the lack of a clear-cut structural approach and the lack of mature computational modeling techniques for the material and structural configurations considered. The evolution of the SCF concepts and corresponding bench-top models will be shown and discussed. Computational models of refined SCF prototypes will be described and representative results will be presented. Structural prototypes that meet the objectives set forth in this study will be demonstrated. Although autonomous stowage/deployment and a balance of stowage force and aerodynamic load sustainment was achieved, formal optimization was not attempted in this study, but is the topic of a related study [4].

\section{NOMENCLATURE}

$\begin{array}{ll}\mathrm{A}_{\mathrm{f}}, \text { As } & \text { Austenite finish/start temperature } \\ \mathrm{c} & \text { Airfoil/wing chord } \\ \mathrm{C}_{\mathrm{P}} & \text { Coefficient of pressure } \\ \mathrm{Cusp} & \text { Lower trailing edge of slat } \\ \mathrm{M}_{\mathrm{f}}, \mathrm{M}_{\mathrm{s}} & \text { Martensite finish/start temperature } \\ \mathrm{OML} & \text { Outer mold line } \\ \mathrm{SCF} & \text { Slat-cove filler } \\ \mathrm{SMA} & \text { Shape memory alloy } \\ \text { Superelasticity } & \text { Pseudoelasticity } \\ \mathrm{TE} & \text { Trailing edge } \\ \mathrm{x} & \text { Airfoil/wing chord-wise coordinate } \\ \alpha & \text { Angle of attack } \\ \sigma^{\text {Af }}, \sigma^{\text {As }} & \text { Austenite finish/start critical stress } \\ \sigma^{\mathrm{Mf}}, \sigma^{\mathrm{Ms}} & \text { Austenite finish/start critical stress }\end{array}$

\section{BACKGROUND}

Consider the flow field in the vicinity of a typical leadingedge slat device, as shown in Figure 1. The flow splits at the stagnation point on the leading surface of the slat, which is in the vicinity of the numeral 3 in Figure 1. The flow progressing on the lower side of the slat (pressure side) separates at the cusp, location 4 in Figure 1, and the resulting shear layer reattaches on the lower surface of the upper part of the slat, forward of the trailing edge. Vortical recirculating flow develops in the cove region of the slat, forward of the shear layer and indicated by 12 in Figure 1. The separated shear layer at the cusp supports the growth of large-scale, flow-instability structures that generate an unsteady fluctuating field. Rapid distortion of these flow structures as they approach the reattachment location and their interaction with the slat TE as they accelerate through the gap are among the potentially important sources of airframe noise [4]-[9]. Additional sources include direct noise radiation from the vortical instabilities in the recirculation region, fluctuations in the reattachment of the shear layer in the slat cove and flow energy conversion as the reattached shear layer separates from the trailing edge.

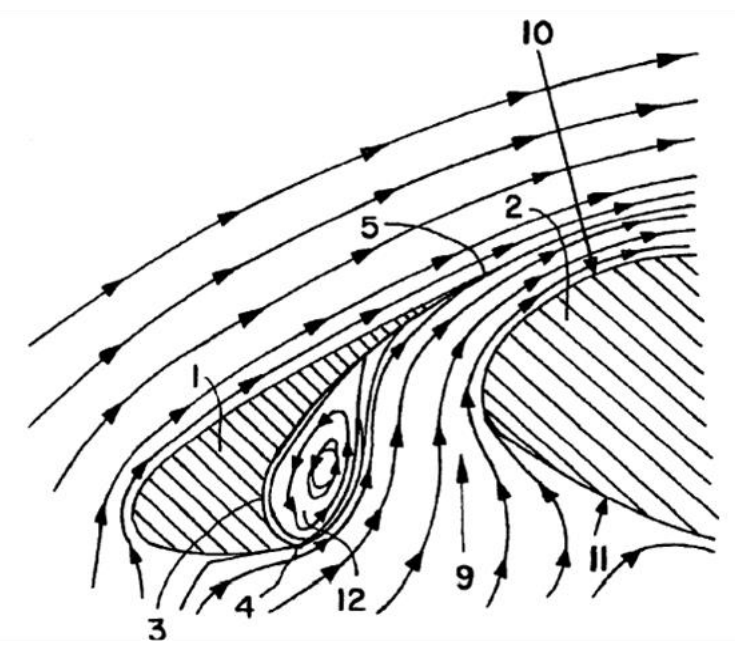

Figure 1: Illustrative flow streamlines in the slat region of a conventional airfoil.

Brushes have been proposed for application at the slat cusp and trailing edge to damp the fluctuating pressures there and reduce the radiated noise [1]. Serrated cusp and trailing edges have been investigated to attempt to produce a similar effect while overcoming the negative impact brushes have at cruise. The concept of an extended blade seal, i.e., a thin extension to the slat cusp, was introduced as a means of guiding the flow in a more desirable manner while leaving the slat, main wing and their nested geometry for a clean cruise configuration relatively unaltered [2]. The serrated-edge and extended-blade-seal approaches are both quite feasible for implementation, but neither approach demonstrated significant noise reduction in a wind-tunnel test [10]. Filling the slat cove is one method that has been shown, both experimentally [10], [11] and computationally [12], to significantly reduce the unsteady aerodynamics and, thus, slat noise.

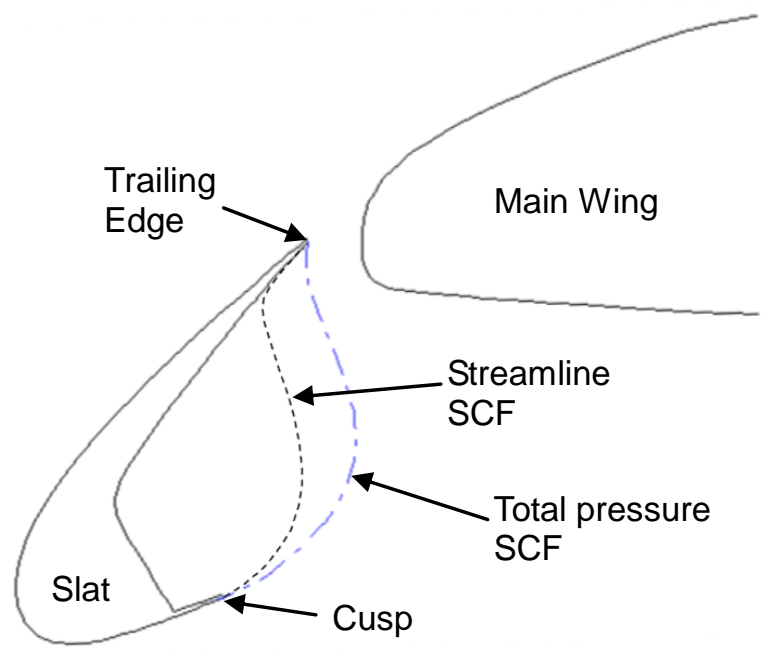

Figure 2: Leading edge of representative aircraft wing with deployed slat and notional SCF profiles.

A two-dimensional schematic of a deployed slat and mainwing geometry, along with two notional SCF profiles are shown in Figure 2. The two SCF profiles were derived from 
streamlines and the total pressure distribution in the flow field between the slat and the main wing. These profiles nominally span the viable range of profiles for concepts considered without modifying the shape of the baseline slat. Although the SCF profile based upon the total pressure distribution is much longer, and correspondingly much more difficult to stow in the available space, previous research suggests that an unmodified baseline slat with a total-pressure SCF achieves the best aerodynamic performance and slat noise reduction.

\section{BENCH-TOP MODEL DEVELOPMENT}

The very large configuration change made it clear that conventional materials and structural approaches were not practical for the SCF application. The variety of possible solutions, the complexity of the potentially-relevant materials and structural configurations, and the requirement for atypical computational models led to a combined physical and computational model approach during concept development. Work was initiated via physical models on the bench top to identify promising approaches. Computational models were then used to refine promising designs.

\section{Design Considerations}

Satisfaction of several conflicting requirements and constraints are essential to the design of an effective slat-cove filler. The SCF structure must achieve the desired profile, upon deployment of the slat, and maintain that profile under aerodynamic load without significant deflection. The SCF must also allow the slat to nest tightly with the main wing and impose no alteration to the outer mold line of the airfoil in the retracted configuration. Other desirable attributes include low weight, passivity (low to no dependence upon auxiliary hydraulics, pneumatics or other actuation), durability, and maintainability.

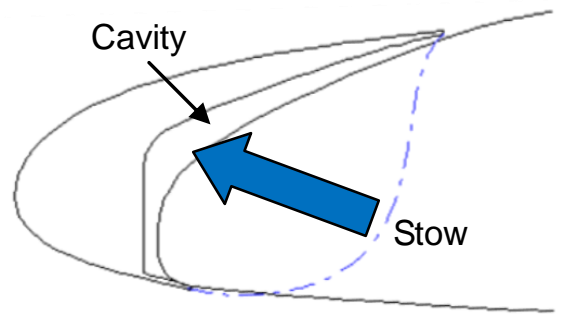

Figure 3: Retracted slat with deployed, total-pressure SCF profile, showing large configuration change requirement.

The most direct and least obtrusive way to stow the slatcove filler structure in the retracted configuration is to contain it within the cavity between the slat and main-wing element. The difficulty involved in this stowage strategy is apparent in Figure 3, where it can be seen that the desirable, total-pressure SCF profile is long and encloses a large volume aft of the slat, compared to the available stowage space. There potentially are many ways to satisfy the requirements and accomplish the objective of stowing the SCF in the cavity between the slat and main wing. Options for stowing that were considered fit into two categories, both involving highly-deformable structures.
The first was an inflatable-type structure that was partially motivated by US 6,394,396 B2 [3]. Second was a shell-type structure that could require a bi-stable functionality, i.e., having separate, stable deployed and retracted configurations that require some initiation to change configuration.

Any approach, consistent with the above, must accommodate large strain in excess of that achievable by conventional structural materials without plastic (permanent) deformation. For example, rough estimates for the maximum strain developed in the total-pressure SCF, shown in Figure 3, during retraction into the cavity were in the range of $2-5 \%$, depending on the structural configuration. Thus, nonconventional materials including hyperelastic (elastomeric) and pseudoelastic (shape memory alloy, SMA) materials were considered for the SCF application.

\section{Hyperelastic (Elastomeric) Materials}

Elastomeric materials are familiar to most people because of their common household and automotive uses. What perhaps is less appreciated by many people is that the variety of commercially available elastomers is huge and that their chemistry and resulting thermomechanical properties vary widely. The most demanding requirement elastomeric materials face in the SCF application is that of providing a compliant constitutive response over a broad temperature range, approximately $-50^{\circ} \mathrm{C}$ to $100^{\circ} \mathrm{C}$. However, many commerciallyavailable silicone and fluorosilicone elastomers are capable of meeting that requirement. Other desirable characteristics include high toughness, wear resistance, chemical (oil, fuel, deicer, etc.) resistance and environmental (UV radiation, water, etc.) resistance. The deformation requirement of the SCF application is not challenging for hyperelastic materials and the deformation range is such that relaxation time is also not considered to be an important issue.

\section{Superelastic SMA Materials}

SMA materials are also becoming well known, particularly in the scientific and engineering communities. SMA materials exhibit a solid-state phase transformation between austenite and martensite in response to changes in temperature and applied stress. The material behavior being exploited in the SCF application is pseudoelasticity (also called superelasticity), where the material is in the austenitic (high-temperature) phase under all operating conditions and is transformed to martensite by applied stress.

Unique features of this material behavior are shown in the idealized $\sigma-\varepsilon$ diagram in Figure 4 [14]. It can be seen that the superelastic SMA material behaves like a conventional, linearelastic material with increasing stress until a critical stress $\left(\sigma^{\mathrm{Ms}}\right.$, which is alloy-chemistry and temperature dependent) is reached. The microstructure begins transforming to martensite at the critical stress level and accommodates large deformation, up to $\sim 7 \%$ without incurring significant plasticity, by reorientation (detwinning) of the martensitic microstructure to variants that are consistent with the applied stress. The 
constitutive behavior reverts to linear-elastic response of detwinned martensite once transformation of the microstructure is complete. Removal of the applied stress is accompanied by recovery of elastic deformation in the detwinned martensite phase followed by the reverse transformation to austenite at another critical stress $\sigma^{\text {As }}$ that is characteristically lower than that for transforming austenite to martensite. Continued reduction of the applied stress results in completion of the reverse transformation to austenite and complete recovery of all deformation, thereby returning the structure to its original configuration upon removal of all stress.

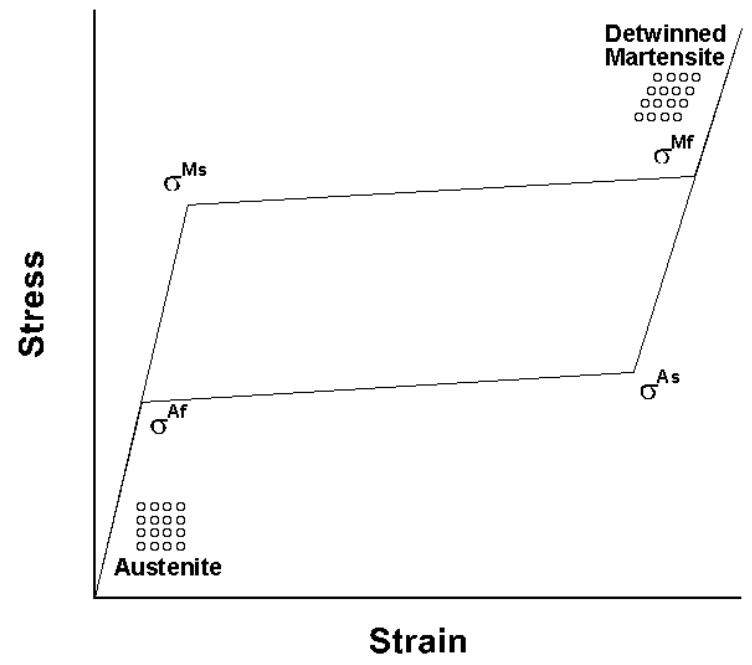

Figure 4: Schematic of the pseudoelasticity effect in shape memory alloys, after Lagoudas [14].

\section{$\underline{\text { Initial Conceptual Study }}$}

A model of a representative, transport-aircraft wing was fabricated at $75 \%$ scale to study SCF concepts. The scale model represented approximately the forward $15 \%$ of the wing and had a span of $\sim 61 \mathrm{~cm}$ with a uniform cross section, i.e., no sweep or taper. Provisions were made to actuate the slat according to the prescribed movement relative to the main wing during deployment and retraction. A pneumatically-assisted, slat-cove filler was developed initially, as shown in Figure 5 and Figure 6, to qualitatively test its efficacy, explore the stowage strategy and explore the parametric space of the application in general. The pneumatic SCF was a relatively thin ( $\sim 3 \mathrm{~mm})$ bladder-type structure consisting of woven, fiberglass fabric embedded in an elastomeric (silicone) host structure. The composite was fabricated by a vacuum-assisted resin infiltration method with a male-female mold positioning the fabric and defining the shape of the elastomeric structure. The SCF was bonded to the slat-cove surface around the perimeter of the SCF.

The pneumatic concept performed nominally as desired as it was put through numerous retraction and deployment cycles using shop air to inflate the SCF during slat deployment. The embedded fabric helped considerably in holding the structure in the prescribed, deployed shape without load and with the low, internal pressurization required for deployment. It was found, however, that relatively-heavy fiberglass fabric was required to constrain the structure to the desired shape even with low internal pressure. It was also found via qualitative assessment that greater pressure and a correspondingly thicker structure were needed to sustain aerodynamic load. In addition, deployment of the structure and sustainment of aerodynamic load is totally dependent upon a source of pressurized gas in the slat. A relatively thin, bladder-type configuration was required in order for the SCF to deform and stow properly between the slat and the main wing, but this thin bladder was vulnerable to being cut, abraded and pinched. A perforation would depressurize the bladder, so chord-wise and span-wise compartmentalization of the bladder was deemed necessary for the actual application. The combination of the extensive structural volume requirement for the pneumatic concept, the need for pressurized gas support with the associated manifold plumbing to accommodate the SCF compartmentalization, and the mass density of relevant elastomers made the concept weight prohibitive.

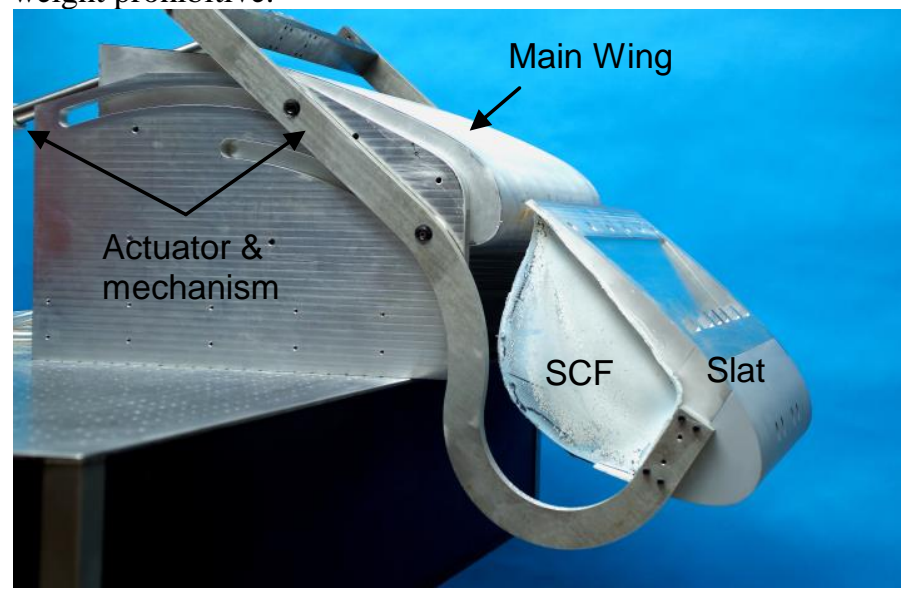

Figure 5: 75\%-scale model of representative-transport airfoil with slat and pneumatic SCF structure deployed.

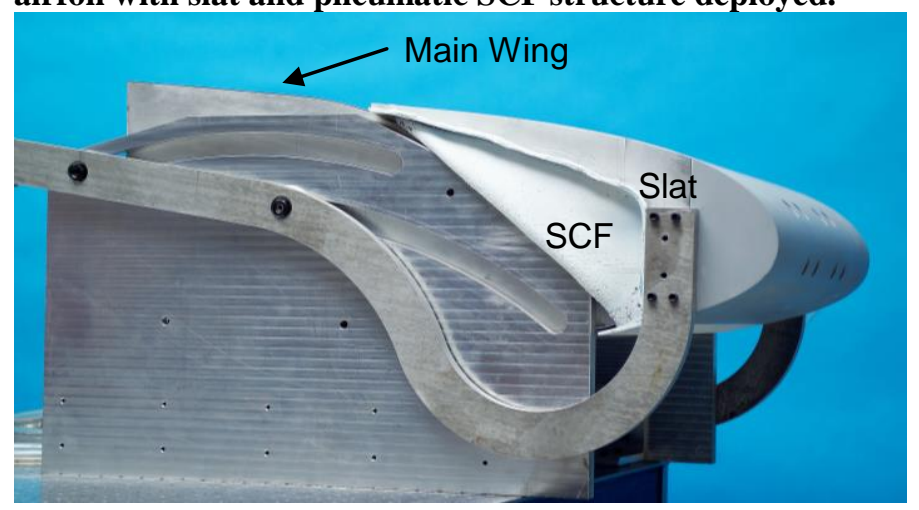

Figure 6: $75 \%$-scale model of representative-transport airfoil with slat and pneumatic SCF structure retracted.

The experience gained from the pneumatic SCF drove attention to a shell-type structure. The first concept that was developed was a blend of hyperelastic and superelastic materials and consisted of SMA ribs $(\sim 0.9 \mathrm{~mm}$ diameter $)$ 
attached to fiberglass mesh and embedded in an elastomeric (silicone) host material. The overall thickness of the SMA-rib SCF was $\sim 2.5 \mathrm{~mm}$. The SMA ribs were positioned on $2.54-\mathrm{cm}$ centers and forced (stressed) to the proper shape by securing the ends of the ribs in appropriately-bored holes in the slat structure at the trailing edge and near the slat cusp, as indicated by "upper rib attachment" and "lower rib attachment," respectively, in Figure 7. These rib connections also served to attach the SCF to the slat. The resulting SCF structure is shown in the deployed configuration in Figure 8.

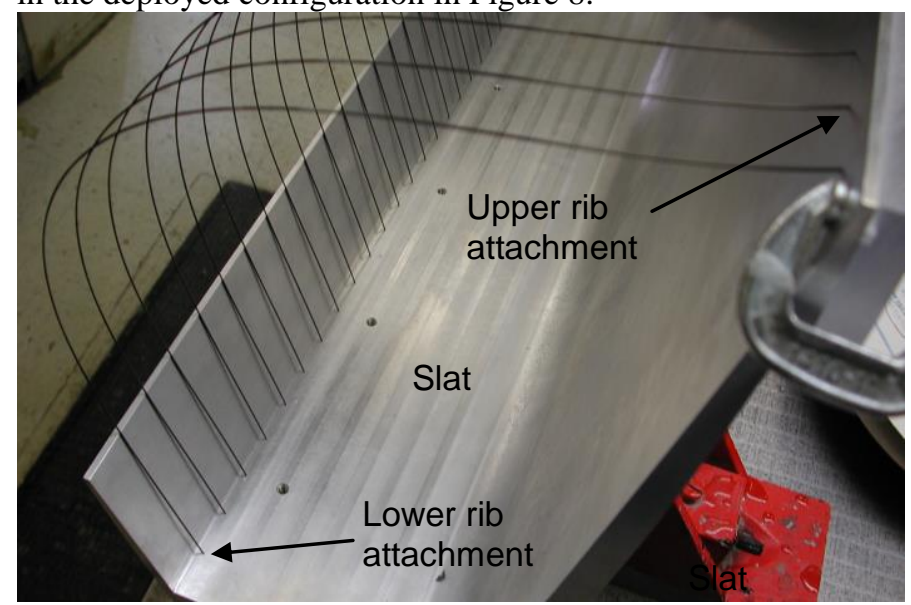

Figure 7: $75 \%$-scale slat model with superelastic SMA ribs installed.

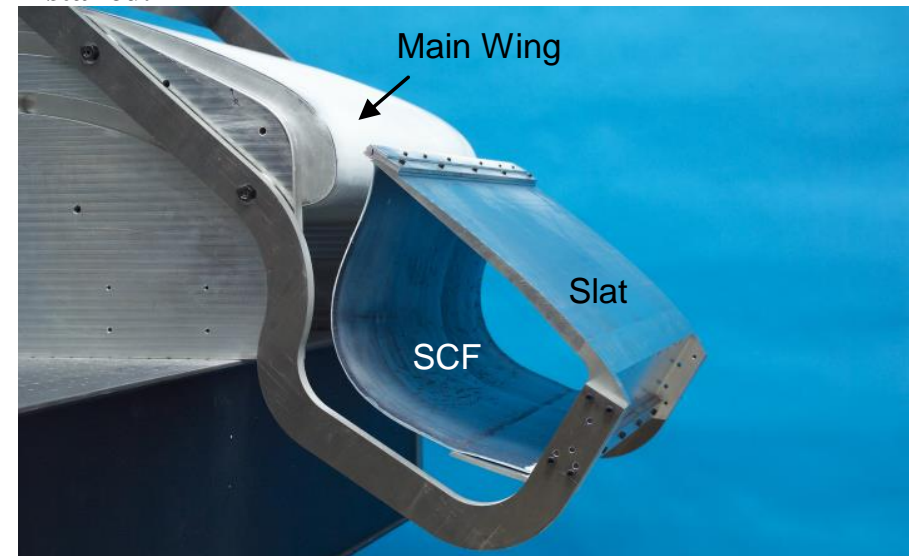

Figure 8: 75\%-scale model with slat and superelastic-SMArib SCF deployed.

Again, deficits in the SCF performance were encountered. The superelastic rib concept lacked sufficient stiffness to sustain the aerodynamic load and it exhibited bi-stable behavior as it would not automatically deploy upon deployment of the slat from the main wing. Additionally, the attachment method forced the SMA ribs into high curvature upon retraction into the slat-wing cavity. The resulting high bending strain exceeded the limit of even the superelastic SMA. Note that, although the slat must always mate with the main wing at the slat cusp, the tight curvature problem was an artifact of the boundary condition imposed on the SMA ribs, which was necessary in this case in order to enforce the proper deployed shape. That situation can easily be avoided by heat treating the SMA ribs to render them stress-free in the desired configuration, thereby allowing freedom in attachment location and approach. The approach to addressing the stiffness deficit entailed decreasing the spacing between the superelastic SMA ribs, noting that this tends to a superelastic sheet in the limit as the spacing goes to zero.

\section{Focused Parametric Study}

Lessons learned from the two initial conceptual studies led to significant changes in the structural approach. The concept development was focused on a thin, shell-type structure capable of large deformation enabled by superelastic SMA materials. It was envisioned that a superelastic SMA sheet would be heat treated (shape set) to render a thin-shell structure that is stress free in the shape of the deployed SCF. The requirement for the slat cusp to come into contact with the main wing in the retracted configuration, for a smooth aerodynamic profile in cruise, was accommodated by introduction of a hinge at the lower attachment location of the SCF to the slat. A lap joint was planned between the SCF and the hinge arm to place the outer surface of the SCF flush with the outer-mold-line of the slat at the cusp. Another lap-joint connection was envisioned for the joint between the SCF and the slat at the trailing edge because of the lack of substantial slat structure there and the tight clearance between the slat trailing edge and the main wing during slat retraction. A schematic of resulting concept is shown in Figure 9.

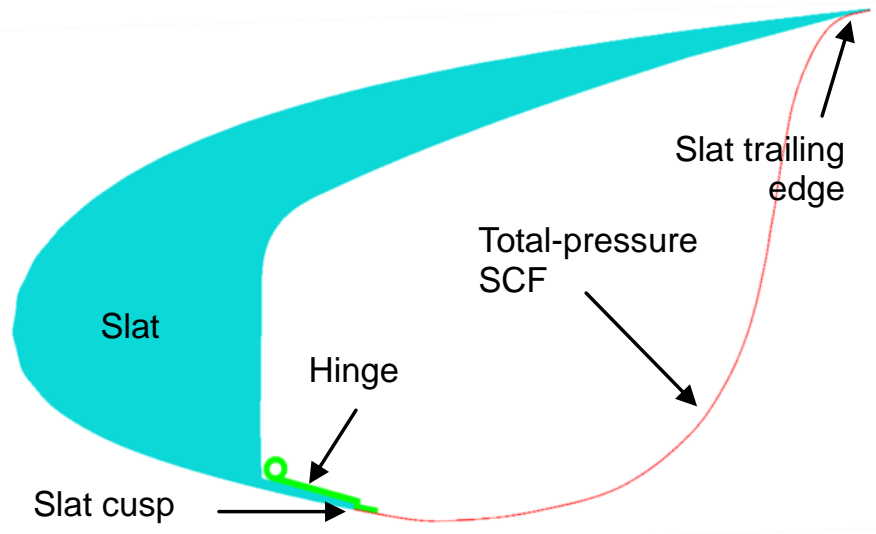

Figure 9: Schematic of deformable, thin-shell SCF concept.

The operational characteristics were envisioned to be as follows. The contact mechanics between the SCF and main wing during retraction of the slat are such that stress is initially concentrated near the trailing edge of the SCF and transformation is induced there first, allowing the SCF to deflect and pass by the main wing. The SCF deforms as needed by transforming in regions of high stress as stowage of the SCF progresses. The stowage force can be minimized by appropriate choice of geometric parameters and transformation characteristics, i.e., SMA chemistry and processing. The large deformation requirement can be accommodated by the transformation-strain mechanism. Friction between the SCF and the main wing can be minimized by coating technologies. 
The restoring force (due to strain energy) developed in the superelastic SMA will deploy the SCF autonomously upon deployment of the slat from the main wing. Additional restoring force can be developed in discrete (e.g., torsional) or distributed (e.g., leaf) bias springs if needed to overcome a bistability condition. The mechanics of the SCF responding to an aerodynamic load is implicitly different from the retractioncontact situation because of the distributed nature of the load and curvature of the structure. Consequently, transformation is not expected under the aerodynamic load and the structure is expected to remain stiff.

It is likely that implementation of a SCF of the type shown in Figure 9 could vary somewhat depending upon the specific airframe configuration. In fact, it was indeterminate at the start of development as to whether a single, monolithic SMA element could constitute the SCF, be configured to function properly (stow and deploy) and sustain the aerodynamic load for the representative airframe considered here. It was foreseen that multiple SMA elements might be required in conjunction with one or more non-deforming elements in order to "program" the stowage process, for the present airframe or others. Thus, a parametric study was planned to interrogate the design space in terms of the number of deforming and non-deforming elements, their relative lengths and their relative thicknesses in order to 1) gain the proper stowage and deployment functionality, 2) minimize the force (and SGF-main wing contact stress) required to stow the SCF, and 3) exhibit acceptable deflections under the aerodynamic load in the deployed configuration.

The bench-top apparatus described earlier was simplified and reduced to a $1.9 \mathrm{~cm}$ span, essentially rendering the apparatus two-dimensional, in order to facilitate more-rapid and less-costly parametric study of the superelastic-SMA SCF concept. In addition, superelastic SMA components available from known vendors were limited to dimensions close to those necessary to fabricate a SCF for the simplified apparatus (still at $75 \%$ scale) shown in Figure 10, i.e., SCF approximately $45 \mathrm{~cm}$ in length. Bearings mounted beneath the slat moved within slots machined into the baseplate to enforce the proper kinematics between the slat and the main wing.

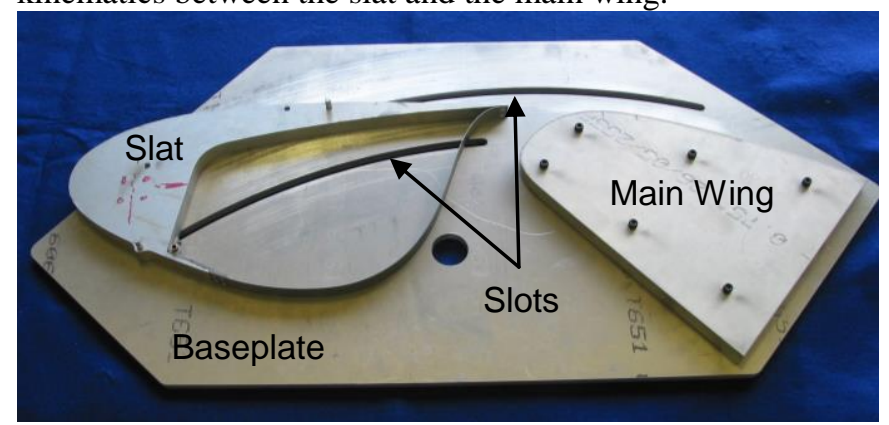

Figure 10: Simplified bench-top apparatus for parametric study of superelastic-SMA SCF prototypes.

Superelastic SMA components, shape-set to the SCF profile, were acquired in thicknesses of 0.5 to $1.27 \mathrm{~mm}$ in $0.127 \mathrm{~mm}$ increments. The components had a composition and heat treatment that resulted in an Austenite finish temperature $A_{f}$ of 0 to $18^{\circ} \mathrm{C}$. Tensile tests were performed by the supplier on sample specimens of the same material from which the components were fabricated. A sample $\sigma-\varepsilon$ diagram is shown in Figure 11. Baseline performance characteristics of the material included a tensile strength $\geq 1.1 \mathrm{GPa}$, a "yield strength" $\geq 379$ $\mathrm{MPa}$, and a "restore strength" in the range of 34 to $241 \mathrm{MPa}$. It is noted that the "yield" and "restore" strengths correspond to the critical stresses for transformation to martensite $\left(\sigma^{\mathrm{Ms}}\right)$ and austenite $\left(\sigma^{\mathrm{As}}\right)$ shown in Figure 4.

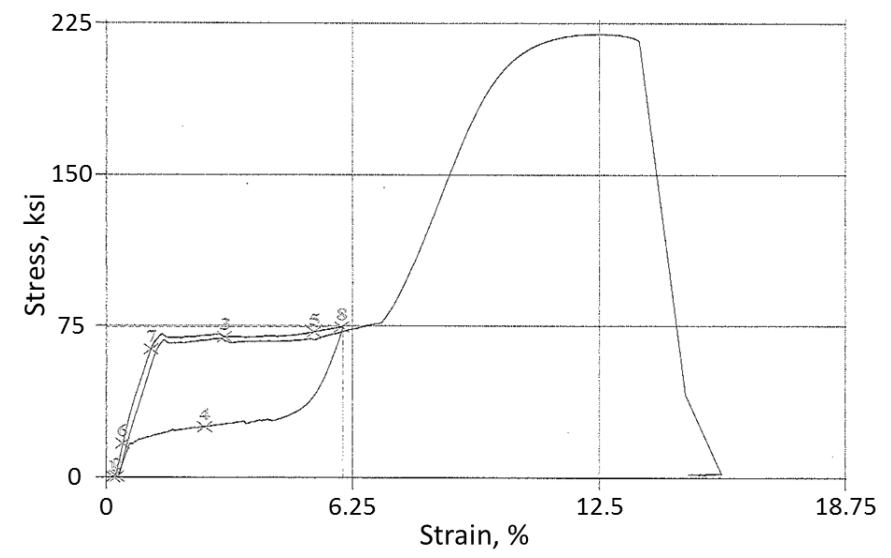

Figure 11: Sample stress-strain data for superelastic SMA material.

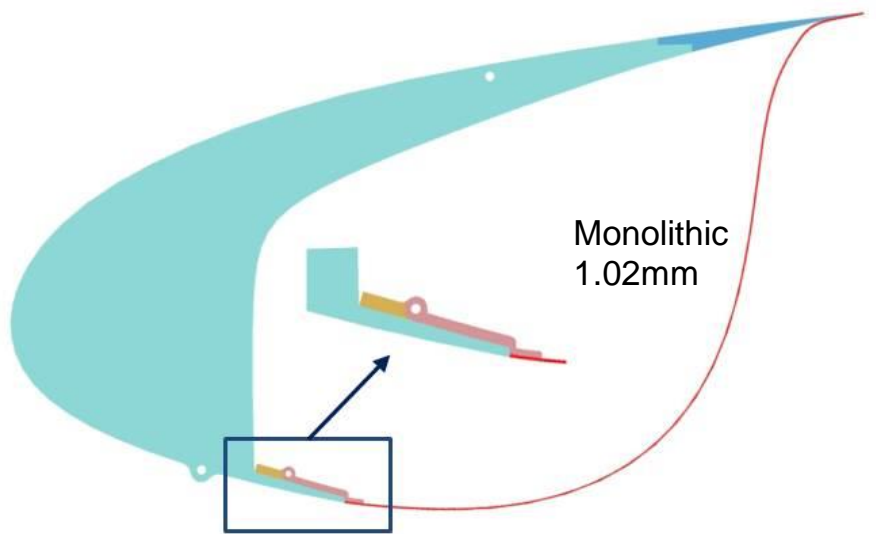

Figure 12: Schematic of 1.02mm-thick, monolithic-SMA SCF and details of hinge joint.

Initial work with the SMA components on the simplified bench-top apparatus led to a down-select of two prototypes; 1) the monolithic prototype (shown in Figure 10 and Figure 12) consisting of a single, superelastic-SMA element spanning the SCF profile from the slat trailing edge to the cusp and 2) the multi-piece prototype (shown in Figure 13) consisting of forward and aft, superelastic, SMA elements separated by a non-deforming intermediate element. The strategic difference between the two prototypes is that the first deforms naturally due to development of stress and the resulting transformation strain, which dictates the shape during retraction. The second employs a stiff element to tailor the stress and deformation fields in order to manipulate the shape during retraction. The position of the hinge axis and length of the hinge arm were 
specifically tailored to maximize the space available for stowage and the mobility of the SCF in these designs.

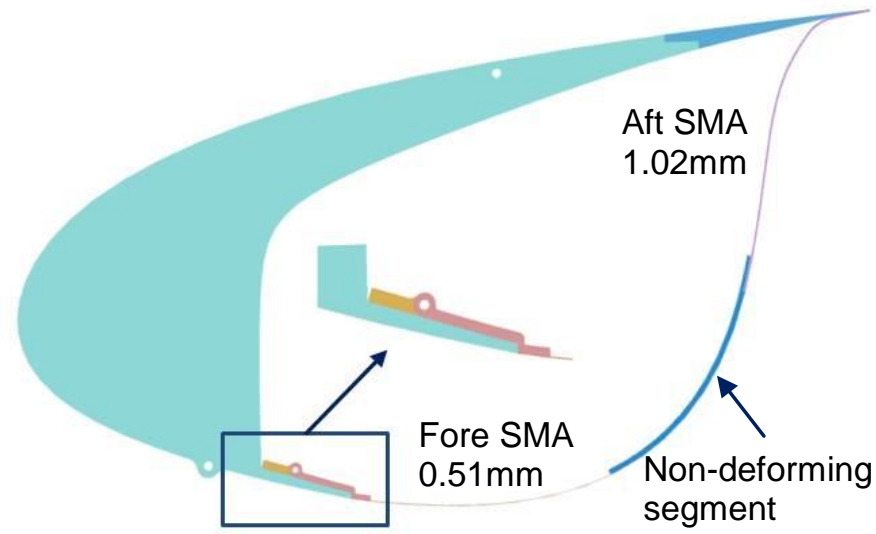

Figure 13: Schematic of multi-piece-SMA SCF having $0.51 \mathrm{~mm}$ - and $1.02 \mathrm{~mm}$-thick forward and aft flexures, respectively, and details of hinge joint.

The initial work on the simplified model also revealed that the additional compliance of the monolithic prototype, relative to the multi-piece prototype, reduced the force required to deform the SCF. This observation is intuitively satisfying as the longer superelastic SMA transforms wherever the critical stress is exceeded and enables the SCF to deform as needed. This was consistent with the original vision and intent of the superelastic SMA structural approach, so an effort was initiated to further extend the length of the monolithic SMA SCF. A graphic of the resulting extended, monolithic concept is shown in Figure 14, where it can be seen that the length of the SMA element has been maximized (and the hinge-arm length minimized) by forming a relatively abrupt "jog" in the SCF to maintain a continuous OML while clearing the slat cusp in connecting to the hinge.

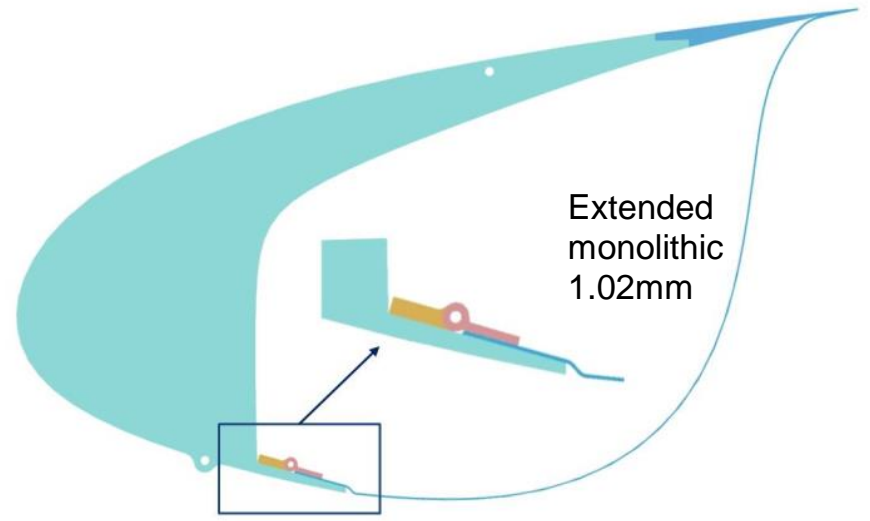

Figure 14: Schematic of extended-length, 1.02mm-thick, monolithic-SMA SCF and details of hinge joint.

It was also discovered in the initial work on the simplified apparatus that relatively minor imperfections in the parts and in the assembly (e.g., fastening) could have a significant effect, i.e., qualitatively identical assemblies exhibited noticeably different behavior. This factor was remedied in later studies by designing a drill alignment apparatus (fixture), shown in Figure
15, which allowed the various parts to be trimmed, configured and co-drilled accurately and precisely. The various detailed features of the apparatus allowed work with the baselinemonolithic, the multi-piece and the extended-monolithic SCF prototypes. Hinge-arm, trailing-edge and intermediate-segment (for the multi-piece prototype) pieces were semi-permanently joined in specific sub-assemblies using the apparatus, as indicated by the interchangeable pieces shown in Figure 12 and Figure 13.

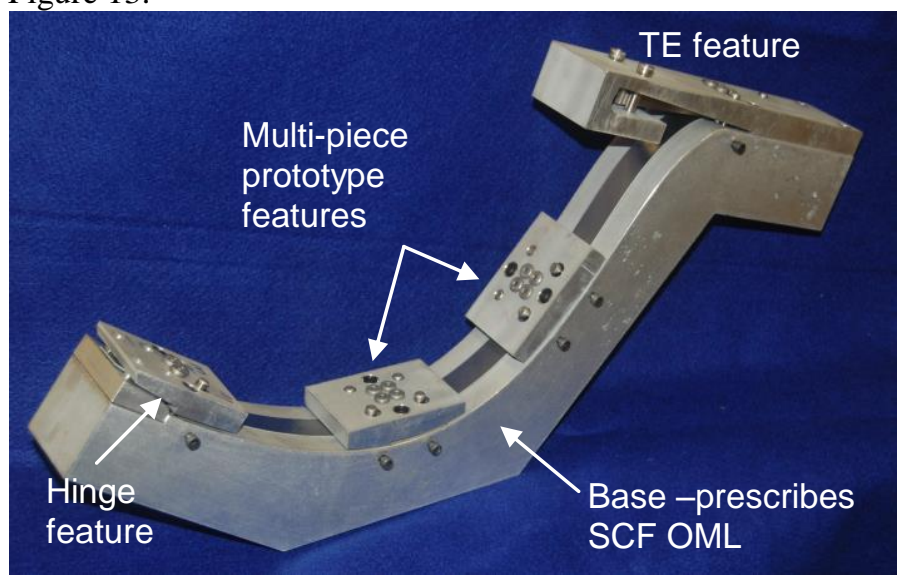

Figure 15: Drill alignment apparatus for accurate and precise fitting and assembly of SCF prototypes.

As a result of the initial work on the simplified bench-top model, additional superelastic SMA components were procured. The new components had the same thickness assortment as listed above and included the extended, monolithic prototype. It is noted that the "jog" feature mentioned above was difficult to produce in the shape-set procedure. Although SMA components with the extended length and "jog" were produced, reduced profile accuracy and additional variability in the components was noted and had to be accommodated. The three prototypes indicated in Figure 12 - Figure 14 were the end result of the physical parametric study on the simplified benchtop model.

The multi-piece prototype consisted of a $1.02 \mathrm{~mm}$ aft SMA element, a $0.51 \mathrm{~mm}$ fore SMA element and a non-deforming intermediate element, each element spanning roughly $1 / 3$ of the overall SCF contour length. This combination was found to be the best candidate and the best compromise among the permutations explored in the parametric space of the multipiece concept because changes in the thickness of either SMA element resulted in a qualitatively unacceptable shift in the balance of force required to stow vs. the ability to resist (stiffness) the aerodynamic load. A pictorial sequence corresponding to the multi-piece apparatus just described is shown in Figure 16. Although this SCF would stow into the cavity with qualitatively-acceptable force, it would not automatically redeploy without an additional bias spring. Introduction of a bias spring would have beneficial effects in resisting the aerodynamic load, but detrimental effects on the force required to stow the SCF. Additional study on the bias spring type, stiffness and placement could provide a good 
balance of these factors. The main advantages of the multipiece approach are the ability to tailor the kinematics of stowage and retraction and the potential to optimize the balance of stowage force versus aerodynamic load resistance.

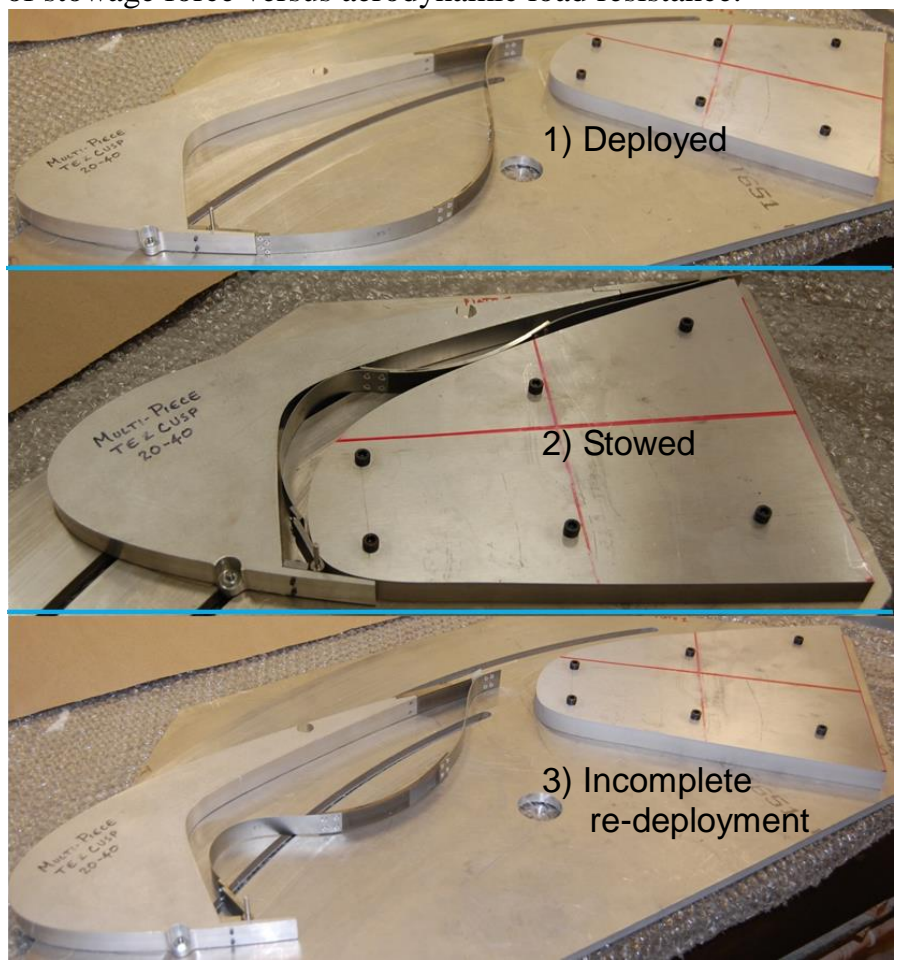

Figure 16: Images of multi-piece-SMA SCF having $0.51 \mathrm{~mm}-$ and $1.02 \mathrm{~mm}$-thick forward and aft flexures, respectively: 1) deployed, 2) stowed and 3) redeployed showing bi-stability behavior.

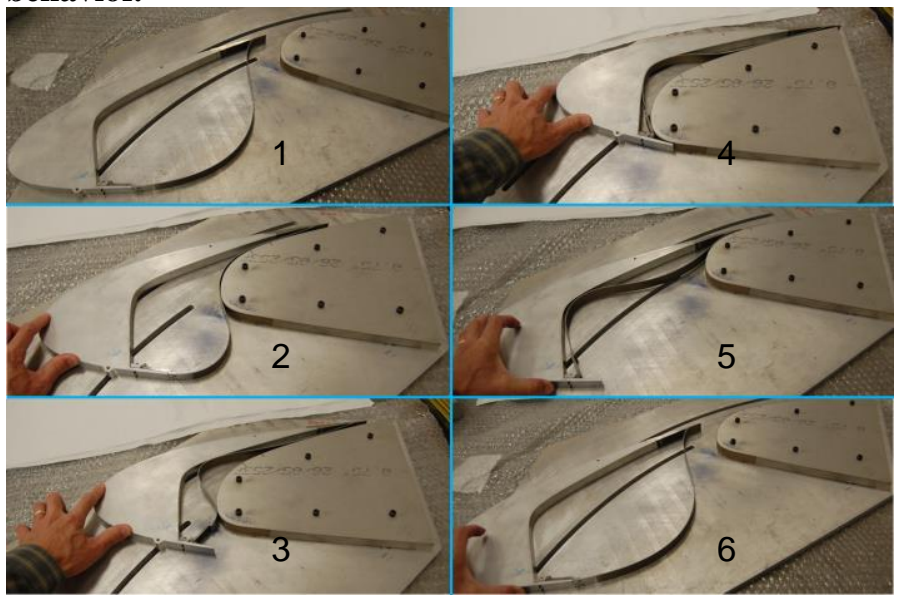

Figure 17: Images of baseline, monolithic-SMA SCF (long hinge arm): 1) deployed, 2) SCF flexing around LE of main wing, 3) hinge clearing LE of main wing, 4) stowed, 5) slat $\sim 75 \%$ redeployed, 6 ) SCF autonomously redeployed.

Both of the monolithic prototypes, the baseline and the extended versions, consisted of a continuous, $1.02 \mathrm{~mm}$ SMA element. Both prototypes stowed and automatically redeployed with movement of the slat and qualitatively met expectations in terms of force required for stowage and resistance to a distributed load. Sequences depicting stowage and deployment of the baseline-monolithic and extended-monolithic prototypes are shown in Figure 17 and Figure 18. There was a noticeable reduction in the force required to stow the extended prototype relative the baseline, because of the additional compliance and mobility, but the two structures were qualitatively very similar in terms of response to a distributed load. This trend was as expected and is attributable to the difference in the mechanics associated with the distributed, aerodynamic load versus the concentrated, contact load during stowage, as described earlier in this section. Thus, the main advantages of the monolithic approach are the simplicity, reliability and smooth kinematic operation because of the more-distributed deformation.

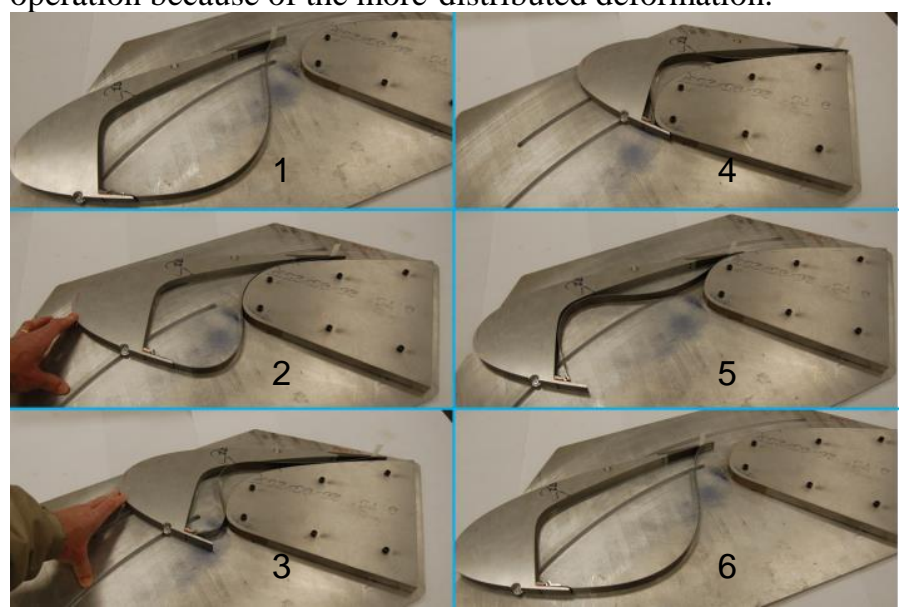

Figure 18: Images of extended, monolithic-SMA SCF (short hinge arm): 1) deployed, 2) SCF flexing around LE of main wing, 3) hinge clearing LE of main wing, 4) stowed, 5) slat $\sim 75 \%$ redeployed, 6) SCF autonomously redeployed.

\section{COMPUTATIONAL MODEL DEVELOPMENT}

A computational modeling component of this work was initiated when the structural approach became focused the superelastic-SMA SCF for detailed study. The objectives of the computational modeling work were to aid in the design process and ultimately provide a comprehensive analysis, design and optimization capability. The analyses performed during this study were those essential to concept demonstration and establishment of feasibility. They included computation of the displacements due to a representative aerodynamic load and simulation of the slat/SCF retraction and deployment process. Only static displacement results from the aerodynamic load will be presented here. Although formal optimization of the SCF designs was not part of this work, it is the focus of a related study [4]. Coupled aeroelastic response was also not considered in this study.

\section{General Model Parameters}

The finite element (FE) models were developed within the framework of SIMULIA Abaqus FEA. The main element, slat and hinge were modeled as discrete rigid surfaces and meshed with R3D3 and R3D4 shell elements. The superelastic-SMA 
and stiff, intermediate components were modeled as deformable shells and meshed with S4R shell elements. The main element, slat, hinge and SCF had global mesh seeds of $\sim 6,6,1.7$ and $3 \mathrm{~mm}$, respectively. Tie constraints were used to model the lap joints between the SCF, the slat trailing edge and the hinge. A hinge connector element was defined for the axis of the hinge to allow it to rotate independent of slat motion.

\section{Displacement due to Aerodynamic Load}

The nature of the simplified, bench-top model shown in Figure 10 and Figure 16 - Figure 18 made it impractical to study the static response of the SCF to a representative distributed load. Static response due to aerodynamic load was, thus, studied computationally. The displacement requirement was established to limit the allowable displacement magnitude to less than $2.54 \mathrm{~mm}$ at any point on the SCF. Experimental data from a scale model representative of the transport-class aircraft considered in this study was used to develop a distributed load [15]. The distribution of the coefficient of pressure $C_{p}$ for the entire airfoil is shown in Figure 19. The angle of attack $\alpha$ was 8 degrees and the freestream Mach number $\mathrm{M}$ was 0.18 .

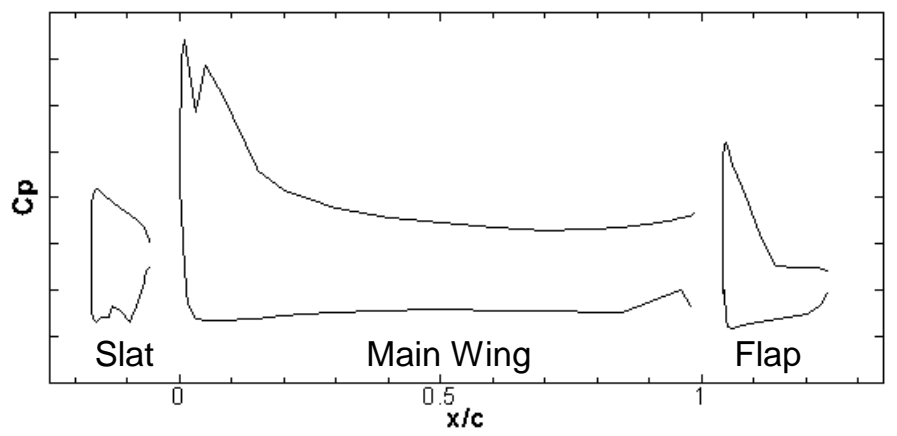

Figure 19: Coefficient of pressure distribution for representative, transport aircraft at $\alpha=8$ and $M=0.18$.

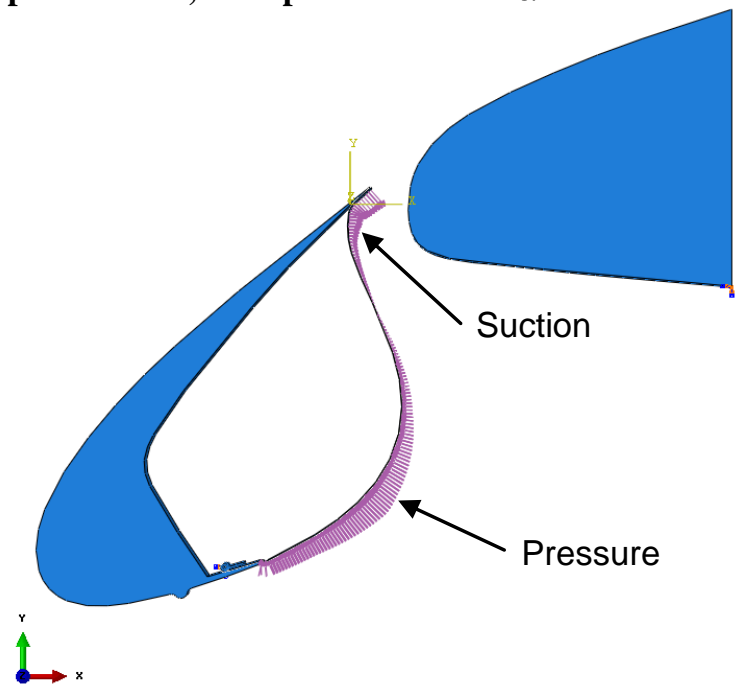

Figure 20: Pressure distribution on the SCF resulting from representative aerodynamics flow.

The Cp distribution was normalized to the $75 \%$-scale model considered in this study and the FE mesh was used to interpolate the pressure distribution onto the model. The pressure was introduced into the FE model as a mapped analytic field, which resulted in the distributed load shown in Figure 20.

The superelastic-SMA components were modeled using an isotropic, linear-elastic material definition under the assumption that the SCF would fail the application due to excessive deflection under the aerodynamic load if transformation was induced anywhere. Material properties for the superelastic SMA were taken as nominal properties corresponding to the Austenitic phase $\left(\mathrm{E}=48 \mathrm{GPa}, \nu=0.33, \rho=6.4 \mathrm{~g} / \mathrm{cm}^{3}\right)$. Nonlinear static analyses were performed to allow for the possibility of large displacements and rotations for the cases depicted in Figure 16 - Figure 18.

The maximum displacement response corresponding to the multi-piece-SMA SCF occurred a few $\mathrm{cm}$ aft of the slat cusp and had a magnitude of $\sim 2 \mathrm{~mm}$, as shown in Figure 21 . The maximum von Mises stress occurred on the inner surface of the SCF just forward of the stiff, intermediate element and had a magnitude of $\sim 39 \mathrm{MPa}$, as seen in Figure 22. This stress was well below the critical stress for transformation to martensite $\left(\sigma^{\mathrm{Ms}} \geq 379 \mathrm{MPa}\right)$, so the assumption of Austenitic properties was found to be valid.

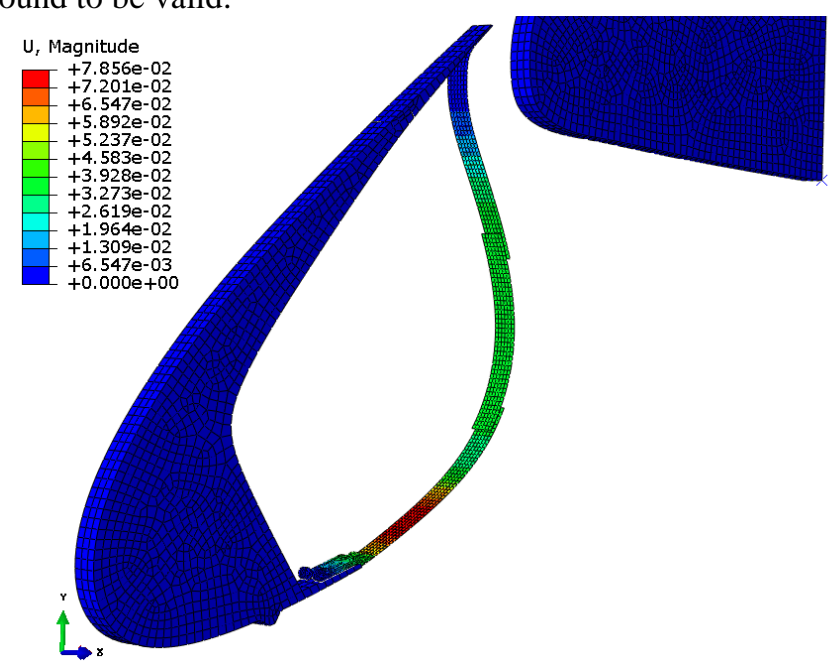

Figure 21: Static displacement response magnitude of the multi-piece-SMA SCF due to aerodynamic load.

The character of the response for the extended, monolithicSMA SCF was slightly different. Peaks in displacement response occurred in two regions; a few $\mathrm{cm}$ aft of the slat cusp and approximately halfway to the TE, and the maximum was $\sim 1.4 \mathrm{~mm}$, as shown in Figure 23. The maximum von Mises stress was $\sim 15 \mathrm{MPa}$, as shown in Figure 24, which occurred on the outer surface of the SCF a few $\mathrm{cm}$ aft of the slat cusp. The maximum stress was again well below the critical stress for transformation to martensite $\left(\sigma^{\mathrm{Ms}} \geq 379 \mathrm{MPa}\right)$. Additional extended, monolithic-SMA SCF models were developed with flexure thicknesses of 0.89 and $0.76 \mathrm{~mm}$ and analysis showed maximum displacement magnitudes of 2.3 and $3.99 \mathrm{~mm}$, respectively. Similar trends were observed for the baseline, monolithic-SMA SCF. 


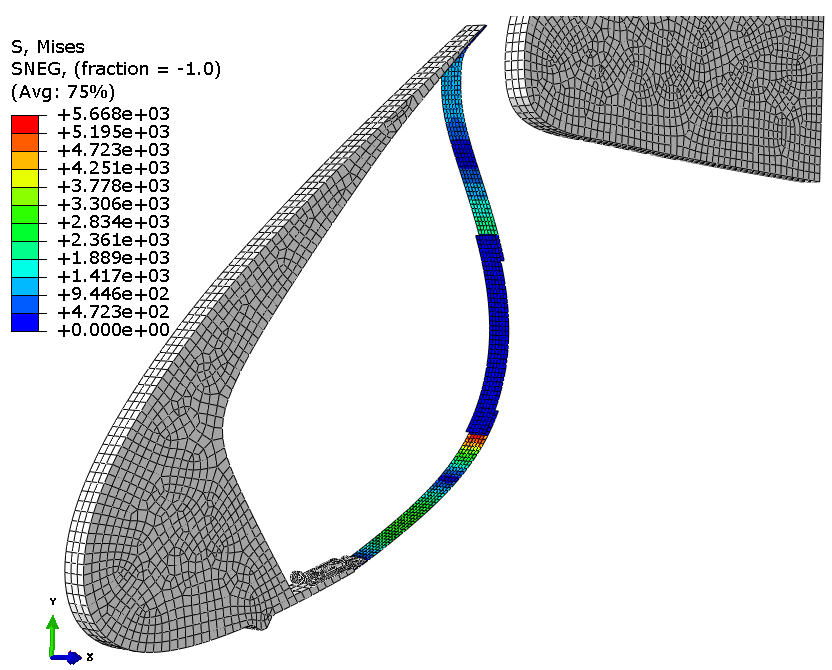

Figure 22: Von Mises stress of the multi-piece-SMA SCF due to aerodynamic load.

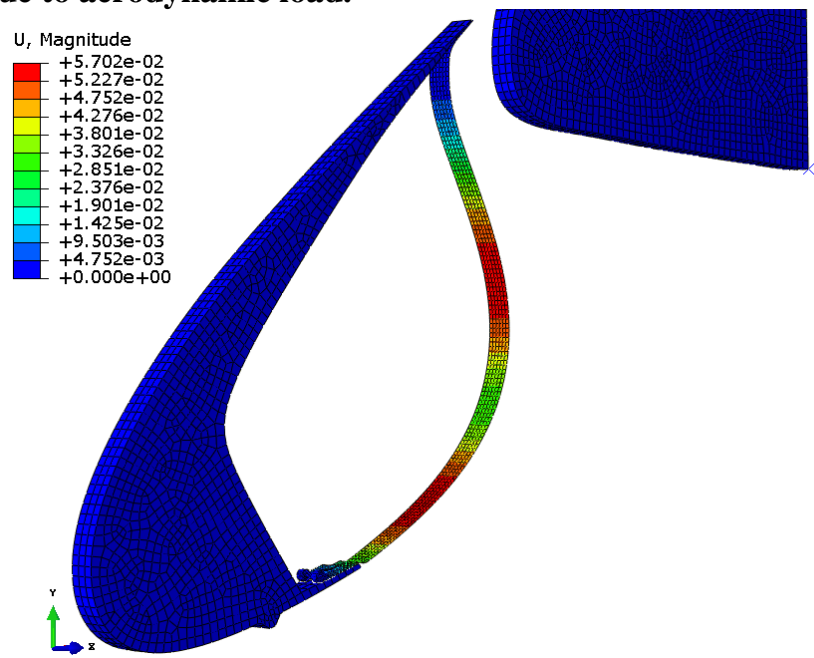

Figure 23: Static displacement response magnitude of the extended, monolithic-SMA SCF due to aerodynamic load.

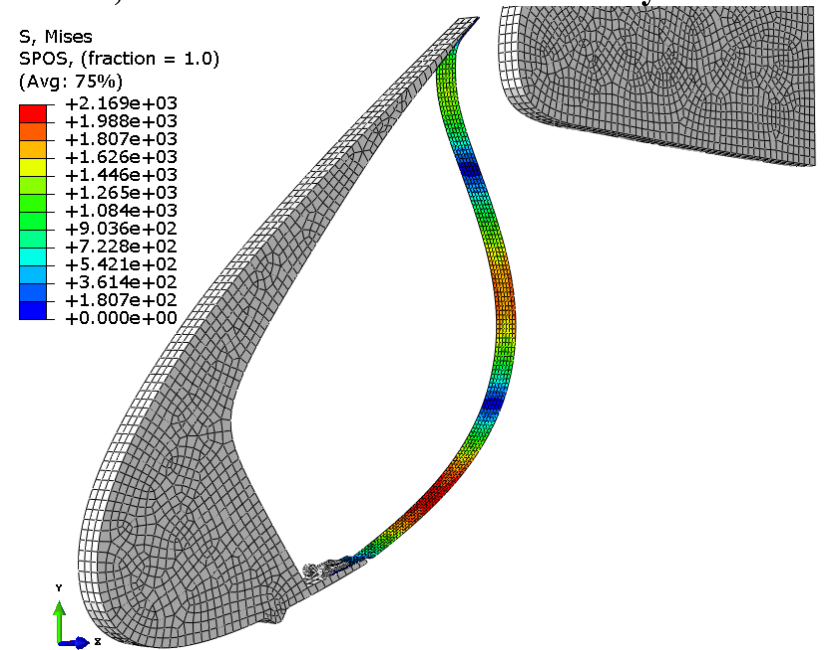

Figure 24: Von Mises stress of the extended, monolithicSMA SCF due to aerodynamic load.
The combination of qualitative, bench-top stowage and deployment results and quantitative computational results for the displacement of the SCF under aerodynamic load suggests that the three SCF designs depicted in Figure 12 - Figure 14 (and Figure 16 - Figure 18) meet the stowage and aerodynamic load requirements. Furthermore, the results suggest that the extended, monolithic-SMA SCF with a thickness of $0.89 \mathrm{~mm}$ may be the best candidate, among those tested, to minimize the stowage force requirements while sustaining the aerodynamic load with satisfactory displacement response.

\section{SUMMARY}

A bench-top model, based upon a typical transport-aircraft wing, was developed at $75 \%$ scale to study the feasibility of developing a functioning slat-cove filler device. Requirements and design constraints mandated novel materials to sustain large deformations. Initial concepts showed significant deficits and led the effort to a shell-type structure enabled for large deformation by superelastic SMA materials.

A qualitative parametric study of SMA-enabled SCF concepts was performed using a bench-top model. Monolithic and multi-piece SMA designs were tested for their ability to stow in the available space between the slat and the main wing and automatically redeploy with deployment of the slat. The force required to stow the structures was also qualitatively assessed. Three SCF designs were selected for further study.

Computational models of the three SCF designs were developed and analyses were performed to assess displacements under representative aerodynamic load. The combination of the qualitative, bench-top results and quantitative computational results suggests that the extended, monolithic-SMA SCF with a thickness of $0.89 \mathrm{~mm}$ may provide the best balance of minimizing the stowage force while maintaining its shape under aerodynamic load.

\section{FUTURE WORK}

Work that remains to be completed includes modifying the bench-top apparatus for mechanization of the slat movement and quantitative measurements of key performance parameters. Measurements will include the force and/or torque required to retract and deploy the slat and response quantities associated with the SCF, such as strain and contact stress. Computational models will be correlated with the experimental measurements and modified as necessary.

\section{ACKNOWLEDGMENTS}

The guidance provided by David Lockard, Mehdi Khorrami and Craig Streett (NASA LaRC) on requirements of the application and on aerodynamics/aeroacoustics in general is greatly appreciated. The assistance of Johnnie West and George Hilton (NASA LaRC) in fabrication, assembly and modification of the bench-top assemblies is also gratefully acknowledged. The assistance of Doug Weber (NASA LaRC), Chris Spreen (Purdue University) and Bruce Storms (NASA ARC) in the initial design of the multi-piece SCF concept, 
initial computational modeling work and establishment of a representative aerodynamic load, respectively, is also greatly appreciated. Support from NASA's Fundamental Aeronautics, Fixed-Wing Project is also gratefully acknowledged.

\section{REFERENCES}

[1] Mau, K. and Dobrzynski, W., 2004, "Flexible Airflow Separator to Reduce Aerodynamic Noise Generated by a Leading Edge Slat on an Aircraft Wing," US Patent No. US 6,789,769 B2, September 14.

[2] Khorrami, M.R. and Lockard, D.P., 2006, "Effects of Geometric Details on Slat Noise Generation and Propagation," AIAA Paper 2006-2664.

[3] Gleine, W., Mau, K., and Carl, U., 2002, "Aerodynamic Noise Reducing Structure for Aircraft Wing Slats," US Patent No. US 6,394,396 B2, May 28.

[4] Scholten, W.D., Turner, T.L., and Hartl, D.H, 2013, "Analysis-Driven Design Optimization of a SMA-Based Slat-Cove Filler for Aeroacoustic Noise Reduction," SMASIS2013-3104, Proc. of the ASME 2013 Conf. on Smart Matl., Adap. Struct. and Intell. Sys., ASME, Snowbird, UT.

[5] Khorrami, M.R., Berkman, M.E., and Choudhari, M., 2000, "Unsteady Flow Computations of a Slat with a Blunt Trailing Edge," AIAA Journal, Vol. 38, No. 11, pp. 20502058.

[6] Singer, B.A., Lockard, D.P., and Brentner, K.S., 2000, "Computational Aeroacoustic Analysis of Slat TrailingEdge Flow,” AIAA Journal, Vol. 38, No. 9, pp. 1558-1564.

[7] Khorrami, M.R., Singer, B.A., and Berkman, M.E., 2002, "Time-accurate Simulations and Acoustic Analysis of Slat
Free Shear Layer,' AIAA Journal, Vol. 40, No. 7, pp. 1284-1291.

[8] Khorrami, M.R., Singer, B.A., and Lockard, D.P., 2002, "Time-accurate Simulations and Acoustic Analysis of Slat Free Shear Layer: Part II," AIAA Paper 2002-2579.

[9] Choudhari, M., Khorrami, M.R., Lockard, D.P., Atkins, H.L., and Lilley, G.M., 2002, "Slat Cove Noise Modeling: A Posteriori Analysis of Unsteady RANS Simulations," AIAA Paper 2002-2468.

[10] Streett, C.L., Casper, J.H., Lockard, D.P., Khorrami, M. R., Stoker, R.W., Elkoby, R., Wenneman, W.F., and Underbrink, J.R., 2006, "Aerodynamic Noise Reduction for High-Lift Devices on a Swept Wing Model," AIAA Paper 2006-212.

[11] Horne, W.C., James, K.D., Arledge, T.K., Soderman, P.T., Burnside, N., and Jaeger, S.M., 2005, "Measurements of 26\%-scale 777 Airframe Noise in the NASA Ames 40- by 80 Foot Wind Tunnel," AIAA Paper 2005-2810, May.

[12] Imamura, T., Ura, H., Yokokawa, Y., Enomoto, S., Yamamoto, K., and Hirai, T., 2007, "Designing of Slat Cove Filler as a Noise Reduction Device for Leading-edge Slat," AIAA Paper 2007-3473.

[13] Otsuka, K. and Wayman, C.M. (Editors), 1998, Shape Memory Materials, Cambridge University Press, Cambridge, UK.

[14] Lagoudas, D.C. (Editor), 2008, Shape Memory Alloys: Modeling and Engineering Applications, Springer Science+Business Media, LLC, New York, NY.

[15] Storms, B.L. et al., 2005, "Aerodynamics of a 26\%-Scale Semi-Span Model of the Boeing 777 in the NASA Ames 40- by 80 -Foot Wind Tunnel," NASA/TP-2005-212829, January. 